ISSN: 2362-1303 (Paper) | eISSN: 2362-1311 (Online)

JOURNAL OF ADVANCED ACADEMIC RESEARCH (JAAR)

June 2020

\title{
Knowledge and Compliance of Iron and Folic Acid Supplementation among Pregnant \& Postnatal Women in a Hospital of Kathmandu Rupesh Kumar Mishra ${ }^{1}$ and Kalpana Tiwari ${ }^{2}$
}

${ }^{1}$ PG students, Department of Nutrition and Dietetics, Purbanchal University, CAFODAT

${ }^{2}$ Professor, Department of Nutrition and Dietetics, Purbanchal University, CAFODAT

\section{Corresponding Author}

Rupesh Kumar Mishra

Email: rups.mishra1396@gmail.com

\begin{abstract}
The high prevalence of iron deficiency anemia and low compliance of iron and folic acid supplementation was reported among pregnant women in Nepal. This study aimed to determine the knowledge and compliance of iron and folic acid supplementation among pregnant and postnatal women in Kathmandu. A descriptive cross-sectional study design was adopted for the study. Sample size was 103 and purposive sampling technique was used to collect the data. All Pregnant women of having above 7 month pregnancy and postnatal's up to 6 months women were included. Data was collected by using self-administered questionnaire .All the obtained data were analyzed with the help of SPSS version 20. Assessment of knowledge revealed that $85.6 \%$ (88) of the participants have adequate knowledge regarding iron and folic acid supplementation .The findings showed 78.6\% (81) of the respondents had iron and folic acid compliance as standard of Nepal government that is to be taken minimum 180 tablet before delivery. It concludes that the level of knowledge and compliance rate of iron and folic acid supplementation in Kathmandu is satisfactory in comparisons to national status i.e. 42\% according to Nepal Demographic health survey 2016. Pearson chi-square test shows that level of knowledge on iron and folic acid tablet is not associated with the compliance of iron and folic acid tablet $\left(\chi^{2}=0.019, \mathrm{p}<0.889\right)$. The main reason of respondents having compliance is due to having proper counseling from health worker and non compliance is due to forgetting to have tablet. Therefore improving knowledge level only can't improve compliance level, various factors like counseling, accessibility and availability of iron and folic acid tablet, side effect of tablet and family support also affects the compliance of iron and folic acid supplementation.
\end{abstract}

\section{KEYWORDS}

Compliance, Iron \& Folic Acid, Knowledge, Postnatal Women, Pregnant

\section{INTRODUCTION}

In pregnancy, anaemia is an important factor associated with an increased risk of maternal, fetal, and neonatal mortality, poor pregnancy outcomes, and impaired cognitive development, particularly in developing countries like our Nepal. Iron deficiency anaemia is major public health problem of Nepal during pregnancy, fetal growth and development, increases the physiological requirement for iron. However, it is difficult for most pregnant women in Nepal to eat a diet that supplies the amount of iron to meet the minimum requirements. Therefore, an effort to increase iron intake through iron supplementation is recognized as the key intervention 
ISSN: 2362-1303 (Paper) | eISSN: 2362-1311 (Online)

JOURNAL OF ADVANCED ACADEMIC RESEARCH (JAAR)

June 2020

to address the problem of anaemia during pregnancy and postpartum period (UNFPA, 2017). The folate (Folic acid) deficiency also causes anaemia and increase a risk of neural tube defects in newborns.

WHO has recommended having daily oral iron and folic acid supplementation with 30 $\mathrm{mg}$ to $60 \mathrm{mg}$ of iron and $400 \mu \mathrm{g}(0.4 \mathrm{mg})$ folic acid for pregnant and postnatal women to prevent maternal anaemia, puerperal sepsis, low birth weight, and preterm birth. Ideally, women should receive iron-containing supplements no later than the first trimester of pregnancy, which means minimum 180 tablets before delivery (WHO, 2016).

There are 1.62 billion anaemic people, which is a quarter of the global population (BMC,2014) .The prevalence of anemia among women has increased in the past 5 years from $35 \%$ in 2011 to $41 \%$ in 2016 . However, the prevalence of anaemia among pregnant women has declined slightly from $48 \%$ in 2011 to $46 \%$ in 2016 . It can be noted that the percentage of pregnant women receiving the recommended dose of IFA tablets during their pregnancy has improved over the period, from 38\% in 2011 to $42 \%$ in 2016 is the reason of improving anemia among pregnant women (NDHS, 2016). Compliance rate of IFA tablet in Nepal according to NDHS 2016 is $42 \%$ which is so less compared to other countries . So it is necessary to find the status compliance rate and factor associated relating to IFA supplementation.

\section{METHODS}

A descriptive cross sectional study design was used to assess knowledge and compliance rate of iron ad folic acid supplementation among pregnant and postnatal women of Kathmandu. The study was conducted at Kathmandu Model Hospital, Kathmandu. The population of the study was pregnant and postnatal women admitted at different ward and came for vaccination for their children and OPD were taken. Sample size was 103 and purposive sampling technique was used to collect the sample. Structure questionnaire was developed by reviewing literature, consulting with research committee. Ethical consideration was obtained from Institutional Review committee of Phect-Nepal to conduct the study. Informed written consent was obtained from each respondent. Data were analyzed by using Statistical Package for Social Sciences (SPSS) version 20. Pearson chi-square test is applied to find out the association between knowledge and compliance rate of iron and folic acid supplementation.

\section{RESULTS}

More than half 51(51.5\%) of respondents were from age group 21-30 years. The mean age of the respondents was 30.58. Forty three respondents (42\%) are pregnant mothers and 60 (58\%) respondents are postnatal. Sixty five percent of respondents replied folic and iron tablet required to pregnant and postnatal women. Near sixty $59(57.3 \%)$ of respondents response that iron and folic acid intake will prevent anaemia. 
ISSN: 2362-1303 (Paper) | eISSN: 2362-1311 (Online)

JOURNAL OF ADVANCED ACADEMIC RESEARCH (JAAR)

June 2020

Table 1: Level of Knowledge among Respondents

$n=103$

\begin{tabular}{|l|c|c|c|}
\hline \multicolumn{1}{|c|}{ Categories } & Level & Frequency & Percentage \\
\hline Inadequate knowledge & $0-7$ & 15 & 14.4 \\
\hline Adequate knowledge & $8-14$ & 88 & 85.6 \\
\hline
\end{tabular}

Table 1 illustrates that $88(85.6 \%)$ of respondents had adequate knowledge where as 15 (14.4\%) of respondents had inadequate knowledge.

Table 2: Level of Compliance on Iron and Folic Acid Tablet among Respondents

$\mathrm{n}=\mathbf{1 0 3}$

\begin{tabular}{|l|l|c|c|}
\hline \multicolumn{1}{|c|}{ Categories } & Level & Frequency & Percentage \\
\hline Non-compliance & Below $180 \mathrm{tab}$ & 22 & 21.4 \\
\hline Compliance & Above $180 \mathrm{tab}$ & 81 & 78.6 \\
\hline
\end{tabular}

Table 2 shows that majority of 81(78.6\%) respondents had compliance on iron and folic acid supplement where as $22(21.4 \%)$ of respondents had non-compliance.

Table 3: Reason of non -compliance on IFA Tablet among Respondents

\begin{tabular}{|l|c|c|}
\hline \multicolumn{1}{|c|}{ Description } & Frequency & Percentage \\
\hline Due to forgetting to have tablet & 12 & 54.54 \\
\hline Due to side effects & 5 & 22.72 \\
\hline Due to its costly price & 2 & 9.09 \\
\hline Due to lack of counseling by health worker & 3 & 13.6 \\
\hline Total & 22 & 100 \\
\hline
\end{tabular}


ISSN: 2362-1303 (Paper) | eISSN: 2362-1311 (Online)

JOURNAL OF ADVANCED ACADEMIC RESEARCH (JAAR)

June 2020

Table 3 shows that majority of $12(54.5 \%)$ respondents had answered the reason of non compliance is due to forgetting to have tablet where $5(22.72 \%)$ answered due to side effects of tablet. Few respondent $2(9.09 \%)$ responded that due to cost.

Table 4: Reason of Compliance on IFA Tablet among Respondents

\begin{tabular}{|l|c|c|}
\hline \multicolumn{2}{|c|}{ n=81 } \\
\hline $\begin{array}{l}\text { Hescription } \\
\text { worker }\end{array}$ & Frequency & Percentage \\
\hline Knowing about its benefits & 24 & 30 \\
\hline Free availability & 22 & 27 \\
\hline Family support & 12 & 28 \\
\hline Total & 23 & 100 \\
\hline
\end{tabular}

Table 4 shows that of $24(30 \%)$ respondents had answered the reason of compliance is due to having proper counseling and $28 \%$ respondents answered due to family support.

Table 5: Association between Level of Knowledge and Compliance on Iron and Folic Acid Intake

$\mathrm{n}=103$

\begin{tabular}{|c|c|c|c|c|c|c|}
\hline \multirow{4}{*}{$\begin{array}{l}\text { Level of } \\
\text { knowledge }\end{array}$} & \multirow[t]{2}{*}{ Categories } & \multicolumn{2}{|c|}{ Compliance } & \multirow[b]{2}{*}{ Total } & \multirow{2}{*}{$\begin{array}{c}\mathrm{X}^{2} \\
\text { Value }\end{array}$} & \multirow{2}{*}{$\begin{array}{c}\mathbf{P} \\
\text { Value }\end{array}$} \\
\hline & & $\begin{array}{c}\text { Non- } \\
\text { compliance }\end{array}$ & Compliance & & & \\
\hline & $\begin{array}{l}\text { Inadequate } \\
\text { knowledge }\end{array}$ & 3 & 12 & 15 & - & $\mathbf{N A}$ \\
\hline & $\begin{array}{l}\text { Adequate } \\
\text { knowledge }\end{array}$ & 19 & 69 & 88 & 0.019 & 0.889 \\
\hline & Total & 22 & 81 & 103 & & \\
\hline
\end{tabular}

Pearson Chi-Square Test

$\mathrm{NA}=$ Chi-Square Test not applicable 
ISSN: 2362-1303 (Paper) | eISSN: 2362-1311 (Online)

JOURNAL OF ADVANCED ACADEMIC RESEARCH (JAAR)

June 2020

Table 5 depicts that those respondents who have adequate knowledge $69(67 \%)$ had compliance with iron and folic acid consumption in another hand 19(18\%) of respondents had non compliance with adequate knowledge. Similarly among those respondents who have inadequate knowledge $3(2.5 \%)$ of respondents had non-compliance where as $12(11 \%)$ of respondent had compliance in iron and folic acid supplementation. The Pearson chi-square test shows that there is no association between level of knowledge and compliance of iron and folic acid consumption $\left(\mathrm{X}^{2}=0.019, \mathrm{P}=0.889\right)$.

\section{DISCUSSION}

This study illustrated the $78.6 \%$ compliance rate of iron and folic acid supplementation which is so much higher than that of compliance of Nepal Demographic and Health Survey (NDHS) report 2016 which was $41 \%$ and another study conducted by Yadav (2019) on topic compliance of iron and folic acid supplementation and status of anaemia during pregnancy in the eastern terai of Nepal, which showed IFA compliance rate was 58\%. These differences could be because of sample size, geographical setting and community area setting in study.

The result of this study was a bit contrast than research conducted on topic effect of knowledge and perception on adherence to iron and folate supplementation during pregnancy in Kathmandu showed 70\% adherence of compliance and knowledge (Thapa and Koju, 2014) and also another study conducted by Ugwo et al., 2012 showed $76 \%$ knowledge and $66 \%$ compliance which both research showed significant associations between knowledge and iron compliance rate, it may be due to difference of private and government hospital setting, counseling, and place difference .

This research supports the study conducted by medical student Rai et al., 2014 conducted at Paropkar maternity hospital which concluded $73 \%$ have Iron and folic acid compliance level. The research also supports the study of Marry (2018). The compliance level not depends with knowledge, different factors like access of IFA availability, economy, counselling, working area, side effects; family support etc also affects compliance level of iron and folic acid supplementation (Marry et al., 2018).

\section{CONCLUSIONS}

Study concluded that all the pregnant and postnatal mother were familiar with iron and folic acid supplementation intervention, they had adequate knowledge and majority of them had compliance on iron and folic acid supplementation which concludes that the compliance level and knowledge level of Kathmandu people is satisfactory. The main sources of iron rich food consumption was green leafy vegetable, pulses legumes, meat products but less access for iron fortified foods.

The Pearson chi-square test shows that there is no association between level of knowledge and compliance of iron and folic acid consumption. It concluded that knowledge level is not only the contributing factor for compliance of IFA supplementation.IFA tablet availability, access, counseling, side effects, family support are other main factors which affects compliance rate of iron and folic acid supplementation.

The research was conducted at limit time and resources at a single hospital which may not represent the rate of Kathmandu. Monthly basis compliance was not measured in this research. The finding of this study will serve as a reference or baseline information for the future research, helps to set target for IFA supplementation and may be helpful to Government of Nepal, National 
ISSN: 2362-1303 (Paper) | eISSN: 2362-1311 (Online)

JOURNAL OF ADVANCED ACADEMIC RESEARCH (JAAR)

June 2020

planning commission, DOHS, MOHP to make plan and policies related with IFA supplementation and anemia reduction.

\section{ACKNOWLEDGEMENTS}

This study has been completed with great support, guidance and cooperation of many individuals and Professors. I would like to provide special thanks to supervisor Dr. Kalpana Tiwari for her valuable theoretical and practical guidance and support throughout the study period. I gratefully acknowledge Dr Ganesh Dangal, Prof. JagatBahadur K.C, Mr. Ishwari Banjade and CAFODAT College for great help.

Finally my special thanks go to my family, and friends for their continuous support, suggestion and encouragement throughout the study.

\section{REFERENCES}

Annual report (2073/74 ). Department of health services, of Nepal MOHP, page 25-99 retrieved from, https://dohs.gov.np/wp-content/uploads/2018/04/Annual_Report 207374.pdf

Charles, O. (2017). Introduction to Biostat and its application, second edition, Wilcox publication, page 12-28

Chourasia, A., Pandey, C., Awasthi, A. (2017). Factors influencing the consumption of iron and folic acid supplementations in high focus states of India, clinical epidemiology and global health. J Clinical Epidemiology and Global Health. Dec 2017, Volume p:180-184

Deo, Y.K., Yadav, U., Wagle, R., Thakur, D. (2019). BMC Journal, Compliance of iron and folic acid supplementation and status of anaemia during pregnancy in the Eastern Terai of Nepal, retrived from, https://bmcresnotes.biomedcentral.com/articles/10.1186/s13104019-4167-6

Kolhari, C.R. (2017). Research methodology for health science, second edition PHI publication, India

Marry, W.K., Marie, W., Samuel, K. (2018). Compliance with Iron and folic acid supplementation, BMC Public Health, 18: 580, doi: 10.1186/s12889-018-5437-2 https://www.ncbi.nlm.nih.gov/pmc/articles/PMC5930505/

MOHP (2013). Health Sector Strategy for Addressing Maternal Undernutrition (2013-17)

Retrivedfromhttps://pdfs.semanticscholar.org/e1a5/f4953b353b0a010cfed81300941c2b3f 3d74.pdf

MOHP Nepal (2002). National strategy for controling anaemia, Available in http://dohs.gov.np/wpcontent/uploads/chd/Nutrition/National_Strategy_for_Anemia_Con trol_EN_13_June_2002.pdf

NDHS Report Nepal (2016). Published by Government of Nepal, from https://www.dhsprogram.com/pubs/pdf/fr336/fr336.pdf

Nisar, Y.B., Alam, A., Michael, J. (2014). Perceptions of antenatal iron-folic acid supplements in urban and rural Pakistan, BMC Journal, retrieved from https://bmcpregnancychildbirth.biomedcentral.com/articles/10.1186/1471-2393-14-344

Rai, S.S., Ratanasiri, T., Thapa, P., Koju, R., Ratanasiri, A., Arkaravichien, T., Arkaravichien, W. (2014). Effect of knowledge and perception on adherence to iron and folate supplementation during pregnancy in Kathmandu, Nepal. J Med Assoc Thai; retrived by https://www.ncbi.nlm.nih.gov/pubmed/25816540 
ISSN: 2362-1303 (Paper) | eISSN: 2362-1311 (Online)

Sah, H., Sherchand, J.B. (2017). Iron Supplementation for Controlling Anaemia in Pregnancy by Involving FCHVs in Saralahi. J NMC, Birgunj, 2(1): 2428. http://www.gjmedph.com/uploads/O7-Vo2No4.pdf

Thapa, P., Kuju, R., Rai, S., Thawalwong, R., Wiwat, A. (204). Effect of Knowledge and Perception on Adherence to Iron and Folate Supplementation during Pregnancy in Kathmandu. Journal of Medical Association, 97 (10), 67-74 https://home.kku.ac.th/cleft/research/JMAT FINAL/JMAT\%20Final\%202014/JMAT\%2 02014\%20Vol\%2097,\%20No\%2010-10.pdf

Ugwo, E.O. ,Olibe, A.O. ,Obi, S.N. (2012). Determinants of compliance to iron supplementation among pregnant women in Enugu, Southeastern ,Niejerian Journal, 17(5), 608-612 http://www.njcponline.com/article.asp?issn=11193077;year $=2014 ;$ volume $=17$; issue $=5$; ppage $=608$; epage $=612$; aulast $=$ Ugwo

UNICEF (2017). Nepals success story, Maternal nutrition retrived from https://www.ennonline.net/attachments/3144/NEX-Asia-1 WEB 14-16.pdf.

UNFPA (2017). NutritionNepal, retrived from https://nepal.unfpa.org/sites/default/files/pub- pdf

Upreti, S., Suvedi, G.R., Paudyal, N., Maharjan, S. (2014). Iron Intensification Program in Nepal: An Overview https://www.spring-nutrition.org/sites/default/files/s upretiiip nepal overview.pdf

WHO (2008). Treatment for anaemia, Reproductive Health Library, retrived by extranet.who.int/rhl/topics/pregnancy-and-childbirth/medical-problems-during-pregnancy

WHO(2012).eLENA,byhttps://www.who.int/elena/titles/guidance_summaries/daily_iron_pregna ncy/en/

WHO (2016). Guidelines,Iron supplementation in postpartum women, retrived from https://apps.who.int/iris/rest/bitstreams/1059308/retrieve 